\title{
RP11-284F21.9 promotes lung carcinoma proliferation and invasion via the regulation of $\mathrm{miR}-627-3 \mathrm{p} / \mathrm{CCAR} 1$
}

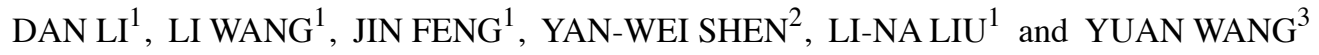 \\ Departments of ${ }^{1}$ Respiratory and Critical Care Medicine, ${ }^{2}$ Medical Oncology and ${ }^{3}$ Medical Imaging, \\ The First Affiliated Hospital of Xi'an Jiaotong University, Xi'an, Shaanxi 710061, P.R. China
}

Received December 6, 2019; Accepted July 10, 2020

DOI: $10.3892 /$ or.2020.7732

\begin{abstract}
Lung carcinoma is a prominent cause of mortality among patients with cancer. Previous studies have reported the vital role of long non-coding RNAs (lncRNAs) in the malignant progression of lung cancer. lncRNA RP11-284F21.9 was originally identified to be expressed in lung carcinoma, but its specific function remains unknown. Therefore, the present study aimed to elucidate the role of IncRNA RP11-284F21.9 in lung carcinoma progression. The expression of RP11-284F21.9 in lung cell lines and tissues was measured using reverse transcription-quantitative PCR. The endogenous expression of RP11-284F21.9 was silenced using RNA interference, and cell viabilities were measured with a Cell Counting Kit- 8 assay. The invasion and apoptosis of cells were determined via Transwell assays and flow cytometry, respectively. The protein expression levels were measured by western blotting. An increased expression of RP11-284F21.9 was identified in both lung carcinoma tissues and cells. Knockdown of RP11-284F21.9 in lung carcinoma cells inhibited cell proliferation and invasion, but promoted cell apoptosis. The present study identified the existence of a direct interaction between RP11-284F21.9 and microRNA (miRNA/miR)-627-3p. Mechanistically, it was demonstrated that RP11-284F21.9 promoted the proliferation and invasiveness of lung carcinoma cells, in part, via the regulation of miR-627-3p. Furthermore, cell division cycle and apoptosis regulator 1 (CCAR1) was identified as a target gene of miR-627-3p. The in vivo tumor growth assay also demonstrated that the knockdown of RP11-284F21.9 suppressed tumor growth, upregulated miR-627-3p and downregulated
\end{abstract}

Correspondence to: Dr Yuan Wang, Department of Medical Imaging, The First Affiliated Hospital of Xi'an Jiaotong University, 277 West Yanta Road, Xi'an, Shaanxi 710061, P.R. China

E-mail: wangyuan8003@126.com

Abbreviations: CCAR1, cell division cycle and apoptosis regulator 1; NSCLC, non-small cell lung cancer; SCLC, small cell lung cancer

Key words: RP11-284F21.9, lung carcinoma, proliferation, invasion, microRNA-627-3p, CCAR
CCAR1 in the xenograft model of nude mice. Thus, the present findings indicated the tumor promoting functions of RP11-284F21.9 in the progression of lung carcinoma, and provided a novel lncRNA/miRNA axis as a target for the management of lung cancer.

\section{Introduction}

Pulmonary malignancies, including lung and bronchus cancer, rank first and second among different cancer types in terms of mortality and morbidity, respectively, in both men and women $(1,2)$. Furthermore, $~ 85 \%$ of lung cancer cases are categorized as non-small cell lung cancer (NSCLC), while the remaining $15 \%$ are classified as SCLC (3). Although diagnostic methods and therapeutic strategies based on traditional surgical excision, chemotherapy and chest radiotherapy have continuously improved, the prognosis of lung carcinoma remains at $15 \%$ for an overall 5-year survival (4). Therefore, an increased understanding of the malignant progression and studies on novel therapeutic targets for the improved management of this disease are essential.

Long non-coding RNAs (lncRNAs) are >200 nucleotides in length and have little or no protein coding capacity (5). The mechanisms via which lncRNAs regulate gene expression are diverse and include regulating the transcription of target genes, functioning as transcriptional precursors of small RNAs, generating different splice variants via regulating mRNA splicing patterns, modulating protein activity and subcellular localization and scaffolding for the assembly of multiple component complexes $(6,7)$.

In recent years, previous studies have reported that various human cancer types exhibit lncRNAs dysfunction, and these lncRNAs are involved in different aspects of pathogenesis such as the proliferation, metastasis and apoptosis of tumor cells $(8,9)$. In lung cancer, lncRNA metastasis-associated lung adenocarcinoma transcript 1 is found to be upregulated in patients with advanced lung adenocarcinoma, and may serve as a prognostic marker to predict the survival outcome of patients with cancer $(10,11)$. IncRNA HOX transcript antisense RNA is also highly expressed in lung cancer (12), and it enhances the aggressiveness of lymph node metastasis and indicates a short disease-free survival in patients with NSCLC $(13,14)$. Furthermore, studies have shown that the expression of IncRNA Urothelial carcinoma-associated 1 
is significantly upregulated in NSCLC, and may induce resistance to treatment of EGFR-tyrosine kinase inhibitors by activating the AKT/mTOR pathway $(15,16)$. IncRNA RP11-284F21.9 was primarily discovered in a Pan-cancer transcriptomic analysis (17). lncRNA RP11-284F21.9 exists as a cluster of three annotated lncRNAs (RP11-284F21.9/.10/.7) antisense to brevican, which is a proteoglycan linked to invasiveness in glioma but lacks expression in squamous cell lung carcinomas (18). However, the specific function and the underlying mechanism of RP11-284F21.9 in lung carcinoma remain unknown.

To the best of our knowledge, the present study demonstrated for the first time that IncRNA RP11-284F21.9 was significantly upregulated in lung carcinoma tissues and cell lines, and was involved in the carcinogenesis of lung cancer. Together with microRNA (miRNA/miR)-627-3p and cell division cycle and apoptosis regulator 1 (CCAR1), the regulatory axis of RP11-284F21.9/miR-627-3p/CCAR1 exists both in the lung carcinoma cells in vitro and in the tumor growth model in vivo. The present study aimed to investigate RP11-284F21.9 function in lung carcinoma and demonstrate the molecular mechanism underlying the regulation process via the RP11-284F21.9/miR-627-3p/CCAR1 axis.

\section{Materials and methods}

Tissue samples and cell lines. Between May 2017 and Jan 2019, paired tumor and adjacent healthy tissues were isolated from 13 patients with lung carcinoma (age range, 35-57 years; nine male patients; four female patients) who were diagnosed and treated in First Affiliated Hospital of Xi'an Jiaotong University. The samples were dissected during the surgery and immediately flash-frozen in liquid nitrogen and transferred to $-80^{\circ} \mathrm{C}$ storage for further extraction of both RNA and protein. All the tissue samples were obtained with written informed consent from the patients. The protocol was approved by The First Affiliated Hospital of Xi'an Jiaotong University (approval no. 201810053).

A normal lung epithelial cell line (BEAS-2B) and lung carcinoma cell lines NCI-H460, NCI-H1299, and A549 were purchased from American Type Culture Collection (ATCC) and cultured according to the ATCC guidelines. 293T cells were purchased from Procell Life Science\&Technology Co., Ltd., and cultured in DMEM supplemented with 10\% FBS (cat. no. 30-2020; ATCC) and 1X Penicillin-streptomycin (Thermo Fisher Scientific, Inc.). BEAS-2B cells were cultured in bronchial epithelial growth medium (BEGM; cat. no. CC-3170; Clonetics Corporation), according to the manufacturer's instructions. NCI-H460 and NCI-H1299 cells were cultured in RPMI-1640 medium (cat. no. 30-2001; ATCC), and A549 cells in F12K medium (cat. no. 30-2004; ATCC) supplemented with 10\% FBS (cat. no. 30-2020, ATCC) and 1X Penicillin-streptomycin (Thermo Fisher Scientific, Inc.). All cells were culture at $37^{\circ} \mathrm{C}$ with $5 \% \mathrm{CO}_{2}$.

$R N A$ extraction and reverse transcription-quantitative $P C R$ $(R T-q P C R)$. Total RNA from both tissue samples and cell lines were extracted using TRIzol ${ }^{\circledR}$ reagent (Invitrogen; Thermo Fisher Scientific, Inc.). For each sample, 500 ng total RNA was reverse transcribed to synthesize the first-strand cDNA using the PrimeScript RT reagent kit (Takara Bio, Inc.).
cDNA samples were diluted 40 times to perform the RT-qPCR using SYBR Premix Ex Taq (Takara Bio, Inc.) on a CFX96 real-time PCR detection system (Bio-Rad Laboratories, Inc.). Expression levels of mRNAs, lncRNAs and miRNAs were normalized to GAPDH. The primers used for RT-qPCR analyses were as follows: GAPDH forward, 5'-AACGACCCCTTCATTGACC-3' and reverse, 5'-TCCACG ACATACTCAGCACC-3'; RP11-284F21.9 forward, 5'-AGG ATTGGCACTCACTTCGG-3' and reverse, 5'-TCTCTCACC ACGTCTGGTCT-3'; and CCAR1 forward, 5'-CTGATGGCT AGCCCTAGTATGGA-3' and reverse, 5'-TGCCTTTCATGC CCACTAAAA-3'. The temperature protocol used to perform RT was $42^{\circ} \mathrm{C}$ for $1 \mathrm{~h}$ followed by $70^{\circ} \mathrm{C}$ for $10 \mathrm{~min}$. Thermal conditions of PCR reactions were: Initial denaturation at $95^{\circ} \mathrm{C}$ for $1 \mathrm{~min}$, followed by 40 cycles for $20 \mathrm{sec}$ at $95^{\circ} \mathrm{C}$ and $60 \mathrm{sec}$ at $60^{\circ} \mathrm{C}$. The mRNA expression levels were determined using the $2^{-\Delta \Delta \mathrm{Cq}}$ method (19).

Oligonucleotides and cell transfection. The small interfering RNA (siRNA) synthetic negative control (si-NC), RP11-284F21.9 siRNAs (si-RP11-284F21.9), miR-NC, miR-627-3p mimics and miR-627-3p inhibitor were purchased from Shanghai GenePharma Co., Ltd.All primer sequence information is presented in Table I. At a density of $2 \times 10^{5}$ cells/well, the cells were plated in 6 -well plates $24 \mathrm{~h}$ before transfection and were transfected at $60 \%$ confluency. All of the oligonucleotides were transfected at a final concentration of $50 \mathrm{nM}$ using Lipofectamine ${ }^{\circledR} 3000$ reagent (Invitrogen; Thermo Fisher Scientific, Inc.) according to the manufacturer's instruction. Cells were collected at $24 \mathrm{~h}$ post-transfection for subsequent experiments.

Cell Counting Kit (CCK)-8 assay and EdU labeling of proliferating cells. A CCK-8 was used for cell proliferation assay, the cells were seeded into 96 -well plates $\left(2 \times 10^{3}\right.$ cells/well $)$ and observed for 1, 2, 3 and 4 days, or indicated time points, following the manufacturer's instructions (Dojindo Molecular Technologies, Inc.). The optical density was measured at $450 \mathrm{~nm}$ using a spectrophotometer (Thermo Fisher Scientific, Inc.).

For the EdU assay, cells were incubated with $10 \mu \mathrm{M}$ EdU (cat. no. ab219801; Abcam) for $2 \mathrm{~h}$ at $37^{\circ} \mathrm{C}$ and fixed with $4 \%$ formaldehyde at room temperature for $10 \mathrm{~min}$. After a brief washing with PBS, click reagent was added into each well and incubated in the dark for $30 \mathrm{~min}$ at room temperature. Followed by PBS washing, the cells were stained with $1 \mu \mathrm{g} / \mathrm{ml}$ DAPI at room temperature for $10 \mathrm{~min}$. Images were captured using a fluorescence microscope (Nikon Corporation) and measured using Adobe Photoshop 6.0 software (Adobe Systems, Inc.). The EdU labeled cells were analyzed with MoFlo Astrios (Beckman-Coulter, Inc.; Magnification, x200).

Transwell assay and flow cytometry measurement of cell apoptosis. Transwell assays were performed with a coating of Matrigel (BD Biosciences) mixed with culture medium mixed at $1: 1$ ratio at $37^{\circ} \mathrm{C}$ for $1 \mathrm{~h}$. A total of $1 \times 10^{5}$ cells in $200 \mu \mathrm{l}$ serum-free medium were added to the upper layer of the Transwell chambers ( $8 \mu \mathrm{m}$ pore size; Corning, Inc.) and cultured for $24 \mathrm{~h}$. The lower chamber contained the culture medium with $10 \%$ FBS. The migrated cells were fixed with 
Table I. Sequence of siRNAs and miRNA mimics and inhibitors.

\begin{tabular}{ll}
\hline Oligonucleotides & Sequence $\left(5^{\prime} \rightarrow 3^{\prime}\right)$ \\
\hline si-NC & UUCUCCGAACGUGUCACGUTT \\
si-RP11-284F21.9 & UAUUGGCACCAAGGAUAGC \\
miR-NC & UCGUUAAUCGGCUAUAAUACGC \\
miR-627-3p mimics & UCUUUUCUUUGAGACUCACU \\
miR-627-3p inhibitor & UCUUUUCUUUGAGACUCACU
\end{tabular}

miR, microRNA; siRNA, small interfering RNA; NC, negative control.

$4 \%$ paraformaldehyde for $30 \mathrm{~min}$ at room temperature, stained with $0.1 \%$ crystal violet for $20 \mathrm{~min}$ at room temperature and images of six randomly selected fields in each well were captured under a light microscope (Magnification, x200).

Cellular apoptosis was detected using the Apoptosis Detection kit (cat. no. KGF001; Nanjing KeyGen Biotech Co., Ltd.) according to the manufacturer's instructions. Cells were stained with fluorescein isothiocyanate-conjugated annexin $\mathrm{V}$ and PI. After incubated for $15 \mathrm{~min}$ at $37^{\circ} \mathrm{C}$ in the dark, $400 \mu \mathrm{l} 1 \mathrm{X}$ Binding Buffer was added to each tube and stained cells were analyzed using BD FACS Canto II flow cytometry (FACS Calibur; BD Biosciences). Data were analyzed using FlowJo software version 8.8.6 (Tree Star, Inc.).

Luciferase reporter assay. The RP11-284F21.9 wild-type (wt) or mutant (mut) 3'-untranslated region (3'-UTR), and CCAR1 wt or mut 3'-UTR sequences were cloned into the pmirGLO plasmid (Youbio; http://www.youbio.cn/; cat. no. VT1439). The vectors $(2 \mu \mathrm{g} / \mathrm{ml})$ were co-transfected with miR-NC or miR-627-3p mimic (50 nM) and Renilla plasmids (5 ng/well), used as an internal control, into cells seeded in a 48-well plate (1x10\% /well) using Lipofectamine ${ }^{\circledR} 2000$ reagent (Invitrogen; Thermo Fisher Scientific, Inc.). Cell lysates were collected at $48 \mathrm{~h}$ after transfection and the luciferase activities were detected with the Dual-Luciferase Reporter Assay system (Promega Corporation) according to the manufacturer's instructions.

Western blotting. Cell were lysed using RIPA lysis buffer (Sigma-Aldrich; Merck KGaA) and protein concentrations were assessed with the BCA Protein Assay kit according to the manufacturer's instructions (Beyotime Institute of Biotechnology, Shanghai, China). Equal amounts $(25 \mu \mathrm{g})$ of cell protein lysates were loaded and separated by $10 \%$ SDS-PAGE, transferred to a PVDF membrane and blocked with $5 \%$ non-fat milk at room temperature for $2 \mathrm{~h}$. The membranes were then incubated with CCAR1 primary antibody $\left(1: 1,000\right.$; cat. no. ab70243; Abcam) overnight at $4^{\circ} \mathrm{C}$, followed by incubation with goat anti-mouse or goat anti-rabbit IgG-horseradish peroxidase conjugate secondary antibodies (1:5,000; cat. no. ab205718; Abcam) at room temperature for 2 h. GAPDH (1:2,000; cat. no. ab181602; Abcam) was used as loading control. The signals were detected using the ECL system (Protein Simple) according to the manufacturer's instructions.
In vivo tumorigenicity analysis in mice. Male BALB/c nude mice (age, 8 weeks; weight, 21-25 g) were obtained from Beijing Vital River Laboratory Animal Technology Co., Ltd., and housed at a room temperature of $25^{\circ} \mathrm{C}$ with a $12 \mathrm{~h}$ light/dark cycle. The mice were maintained in an individually ventilated cage system under specific pathogen-free conditions (temperature; $25^{\circ} \mathrm{C}$; humidity: $55 \%$ ), and fed with sterile food and water (free access). To evaluate the effect of RP11-284F21.9 knockdown on the growth of lung carcinoma in vivo, $5 \times 10^{6}$ si-NC or si-RP11-284F21.9 treated NCI-H1299 cells in $200 \mu 1$ serum-free medium were subcutaneously injected into each mouse ( $n=5$ per group) under anesthesia, which was induced by $5 \%$ isoflurane and maintained by $2 \%$ isoflurane (flow rate, $11 / \mathrm{min}$ ). The animals were monitored daily and the following criteria for humane endpoint was used: Severe tumor burden (>20 mm in diameter), difficulty breathing, significant body-weight loss and clinical signs such as prostration, hypothermia and significant abdominal distension. Tumors were measured on days 1, 5, 9 and 13, and the volumes were calculated using the formula: $\mathrm{x} \mathrm{b}^{2} / 2$ [the largest diameter (a) and the smallest diameter (b)]. Then, 2 weeks after inoculation, the mice were euthanized by $\mathrm{CO}_{2}$ inhalation $\left(\mathrm{CO}_{2}\right.$ flow rate, $10 \%$ of cage volume) and the death of animals were confirmed by cessation of heartbeat. The xenografts were imaged and weighed.

The total RNA was then extracted from the xenografts as aforementioned. Animal care and study were approved by the Institutional Animal Care and Use Committee of The First Affiliated Hospital of Xi'an Jiaotong University (approval no. 201902013).

Target prediction. Potential target miRNAs of RP11-284F21.9 were predicted using LncBase V2 (http://carolina.imis.athenainnovation.gr/diana_tools/web/index.php? $r=1$ ncbasev2/index). The target genes of miR-627-3p were predicted using three bioinformatics algorithms: TargetScanV7.2 (http://www.targetscan. org/vert_72/) and miRDB (http://www.mirdb.org/mining.html).

Statistics analysis. Data were analyzed using the GraphPad Prism 5.0 software (GraphPad Software, Inc.), and presented as the mean $\pm \mathrm{SD}$ from $\geq 3$ independent experiments. A two-tailed unpaired Student's t-test or one-way ANOVA with Tukey's post-hoc analysis were performed to evaluate the statistical significance. $\mathrm{P}<0.05$ was considered to indicate a statistically significant difference. 
A

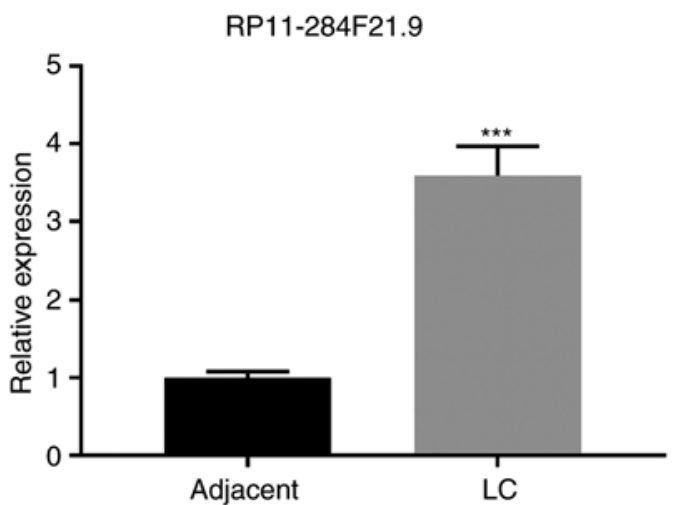

B

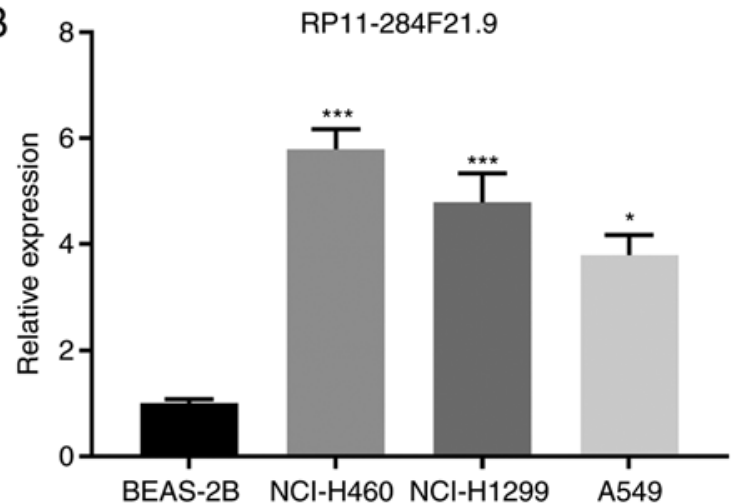

Figure 1. RP11-284F21.9 expression is upregulated in LC tissues and cell lines. (A) Expression of RP11-284F21.9 in LC tissues in comparison with adjacent healthy tissues was analyzed using RT-qPCR. ${ }^{* * *} \mathrm{P}<0.001$ vs. adjacent tissues $(\mathrm{n}=13)$. (B) Expression of RP11-284F21.9 in human lung carcinoma cell lines (NCI-H460, NCI-H1299 and A549) compared with normal human lung epithelial cell line (BEAS-2B) was analyzed using RT-qPCR. ${ }^{*} \mathrm{P}<0.05,{ }^{* * * *} \mathrm{P}<0.001$ vs. BEAS-2B ( $\mathrm{n}=3)$. LC, lung carcinoma; RT-qPCR, reverse transcription-quantitative PCR.

\section{Results}

Expression of RP11-284F21.9 is upregulated in lung carcinoma. To investigate the potential role of RP11-284F21.9 in lung carcinoma, its expression was analyzed in tissue samples and matched adjacent healthy tissues from 13 patients with lung carcinoma. The results demonstrated that the expression of RP11-284F21.9 was significantly upregulated in tumor tissues compared with healthy tissues (Fig. 1A). The expression of RP11-284F21.9 was also analyzed in human lung carcinoma cell lines (NCI-H460, NCI-H1299 and A549) and normal human lung epithelial cell line (BEAS-2B). Consistent with the findings in the tissue samples, the expression of RP11-284F21.9 was significantly increased in carcinoma cell lines compared with the normal epithelial cell line (Fig. 1B). These results indicated that RP11-284F21.9 may serve an oncogenic role in lung carcinoma.

Knockdown of RP11-284F21.9 exerts anti-oncogenic effects in lung carcinoma cells. To study the specific role of RP11-284F21.9 in lung carcinoma cells, RP11-284F21.9 siRNA was transfected into NCI-H1299 and NCI-H460 cells (Fig. 2A). After transfection, the proliferation of these cells was measured using CCK-8 and EdU assays (Fig. 2B-D). The results suggested that knocking down RP11-284F21.9 significantly reduced the proliferation of lung carcinoma cells compared with the NC group (Fig. 2B-D). The invasiveness of si-RP11-284F21.9 transfected cells also significantly decreased, as indicated by the data from the Transwell assay (Fig. 2F). To further validate the invasive capability, a RT-qPCR assay was performed to detect the expression levels of invasion-related genes, and the results identified that both MMP2 and MMP9 were significantly decreased when RP11-284F21.9 was downregulated (Fig. S1).

The results of flow cytometry measurement based apoptosis assay suggested that cells transfected with si-RP11-284F21.9 had a higher apoptotic rate compared with the si-NC transfected group (Fig. 2E). These data demonstrated the anti-tumor effects of RP11-284F21.9 knockdown in lung carcinoma cells, indicating an oncogenic role of RP11-284F21.9.
RP11-284F21.9 directly interacts with miR-627-3p. Based on the prediction of the online tool lncBase v. 2 from DIANA (Prediction module; http://carolina.imis.athena-innovation. gr/diana_tools/web/index.php?r=lncbasev2/index), which was used to identify the downstream miRNAs of RP11-284F21.9, the first five miRNAs in the output list were tested. Among the predicted potential targets, it was found that miR-627-3p had the most significant upregulation in NCI-H1299 cells transfected with si-RP11-284F21.9 (Fig. S2).

Using sequence alignment, it was identified that miR-627-3p was partially complementary with the 3'-UTR of RP11-284F21.9 (Fig. 3A). Subsequently, 293T cells were transfected with the pmirGLO-RP11-284F21.9-wt or mut vector, containing the wt or mut sequence of RP11-284F21.9 3'-UTR, with or without miR-627-3p mimics. Results from the luciferase reporter assay suggested that miR-627-3p mimics significantly decrease the signal of RP11-284F21.9-wt transfected cells but not the RP11-284F21.9-mut transfected cells, indicating a direct interaction between the two non-coding RNAs (Fig. 3A). Furthermore, transfection of si-RP11-284F21.9 into NCI-H1299 and NCI-H460 cells resulted in the suppression of endogenous RP11-284F21.9, leading to a significant increase in miR-627-3p expression (Fig. 3B). Thus, these findings suggested an inhibitory effect of RP11-284F21.9 on the expression of miR-627-3p in lung carcinoma cells.

The expression of miR-627-3p was detected in both lung carcinoma tissues and cell lines. It was demonstrated that miR-627-3p was significantly downregulated in carcinoma tissues (Fig. 3C) and NCI-H460, NCI-H1299, and A549 cells (Fig. 3D) compared with healthy tissues and cells. Collectively, these data suggested a direct interaction between RP11-284F21.9 and miR-627-3p, in which RP11-284F21.9 suppresses the expression of miR-627-3p.

RP11-284F21.9 regulates the proliferation and invasiveness of lung carcinoma cells via miR-627-3p. To rescue the anti-tumor effects of si-RP11-284F21.9 in lung carcinoma cells, the miR-627-3p inhibitor, which specifically downregulates the expression of miR-627-3p, was transfected into NCI-H1299 and NCI-H460 cells (Fig. 4A). The results from the CCK-8 and EdU assays demonstrated that treatment with si-RP11-284F21.9 


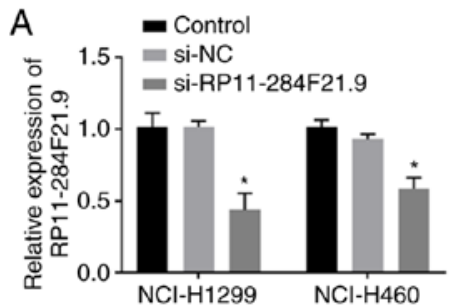

B

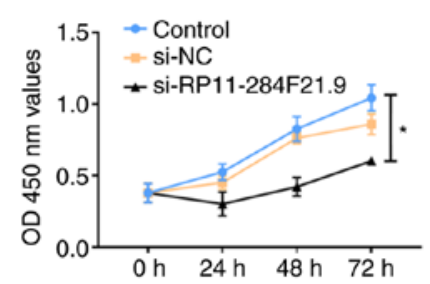

C

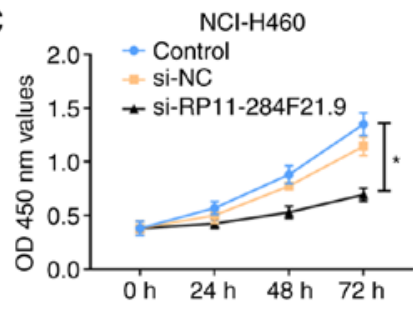

D

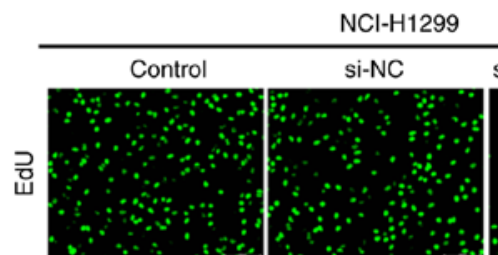

si-RP11-284F21.9
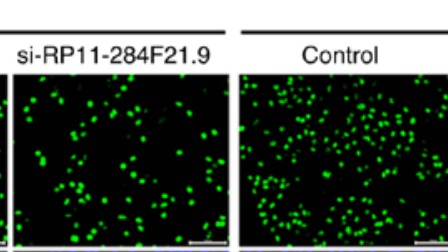

$\mathrm{NCl}-\mathrm{H} 460$

si-NC si-RP11-284F21.9
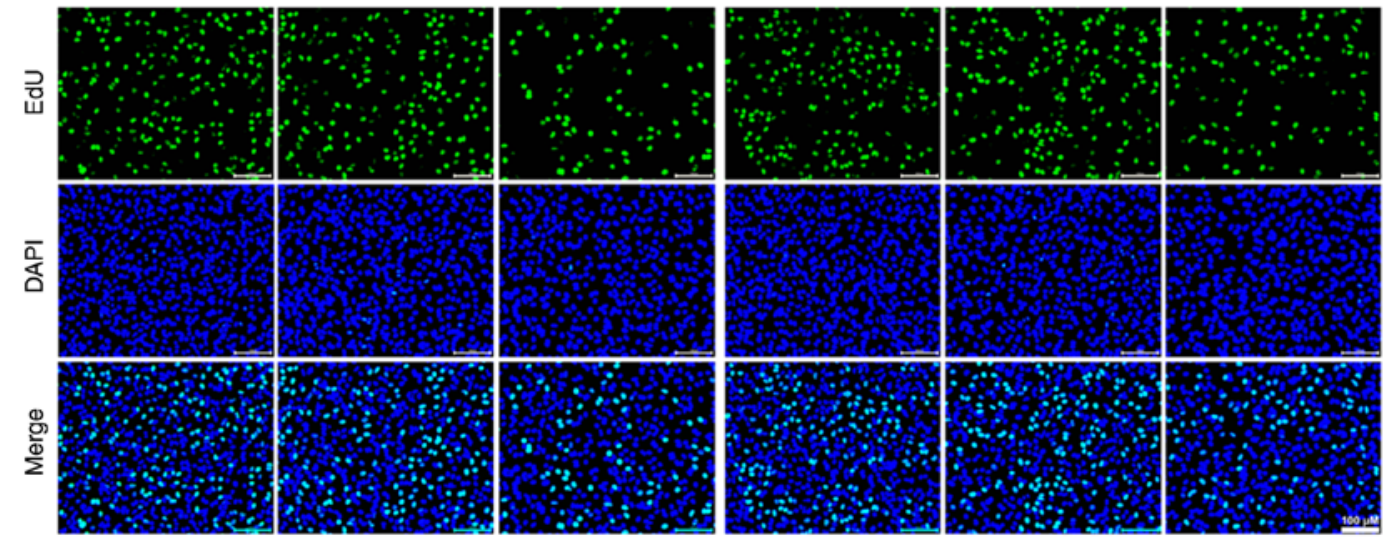

$\mathrm{E}$
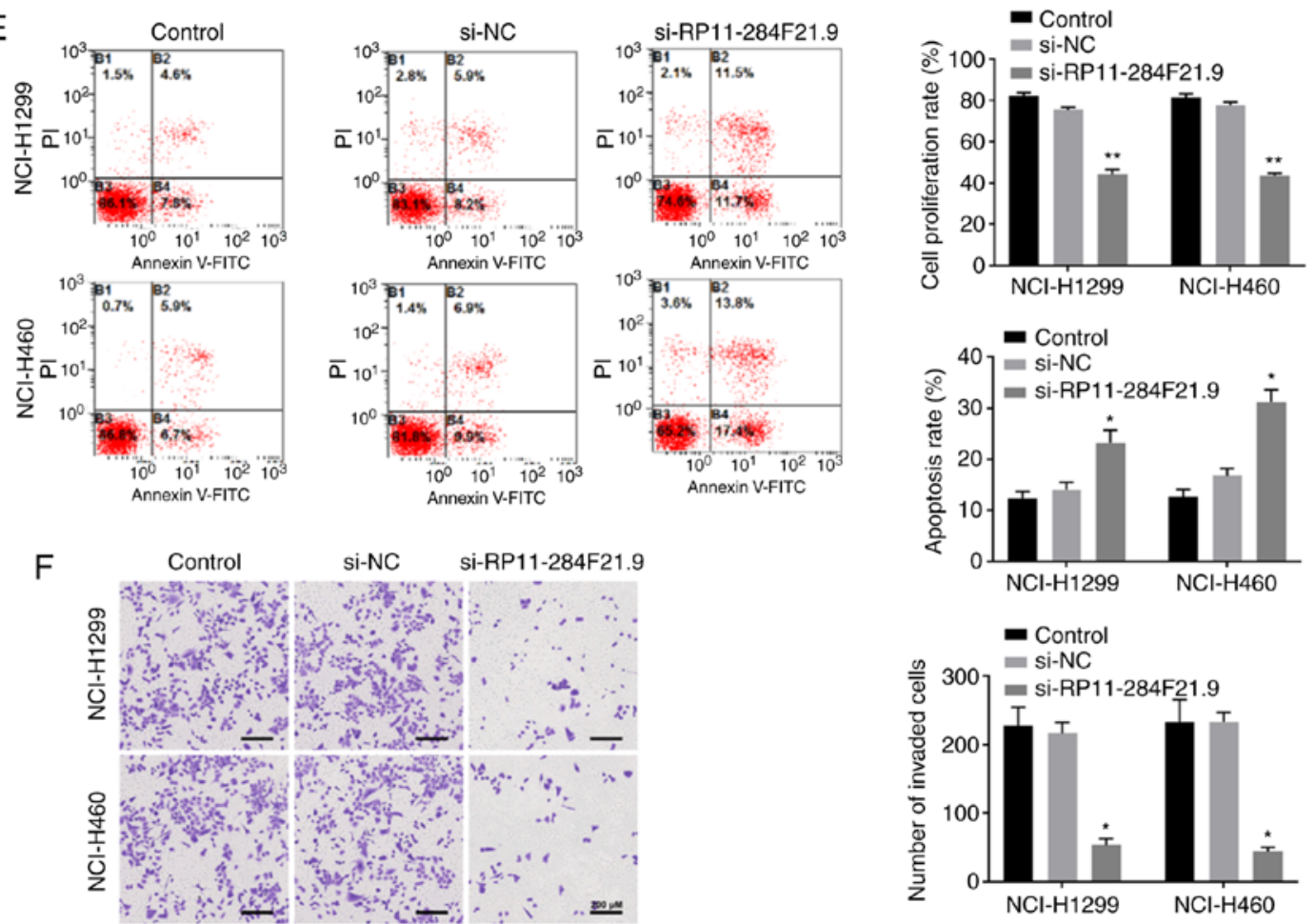

Figure 2. RP11-284F21.9 knockdown inhibits lung carcinoma cell proliferation and invasion, and promotes cell apoptosis. (A) RP11-284F21.9 knockdown was achieved via RP11-284F21.9 siRNA, and the knockdown efficiency was verified using reverse transcription-quantitative PCR (n=3). Cell Counting Kit-8 assay was performed to measure the proliferation of (B) NCI-H1299 and (C) NCI-H460 cells after transfection with si-RP11-284F21.9, compared with the si-NC group (n=5). (D) An EdU assay was performed to measure the proliferation of NCI-H1299 and NCI-H460 cells after transfection with si-NC and si-RP11-284F21.9. Magnification, x200. (E) Flow cytometry analysis was performed to determine the effects of RP11-284F21.9 knockdown on apoptotic rates in NCI-H1299 and NCI-H460 cells (n=3). (F) Transwell assay was performed to determine the effects of RP11-284F21.9 knockdown on NCI-H1299 and NCI-H460 cell invasion ( $\mathrm{n}=3$ ). Magnification, $\mathrm{x} 200{ }^{*} \mathrm{P}<0.05,{ }^{* *} \mathrm{P}<0.01$ vs. control group. NC, negative control; siRNA, small interfering RNA; OD, optical density.

and miR-NC significantly decrease the proliferation of both NCI-H1299 and NCI-H460 cells (Fig. 4B-D). However, the administration of miR-627-3p inhibitor partially reversed the anti-proliferative effect of si-RP11-284F21.9, indicating that RP11-284F21.9 regulates the proliferation of lung carcinoma cells partially via miR-627-3p (Fig. 4B-D). In addition, the 
A

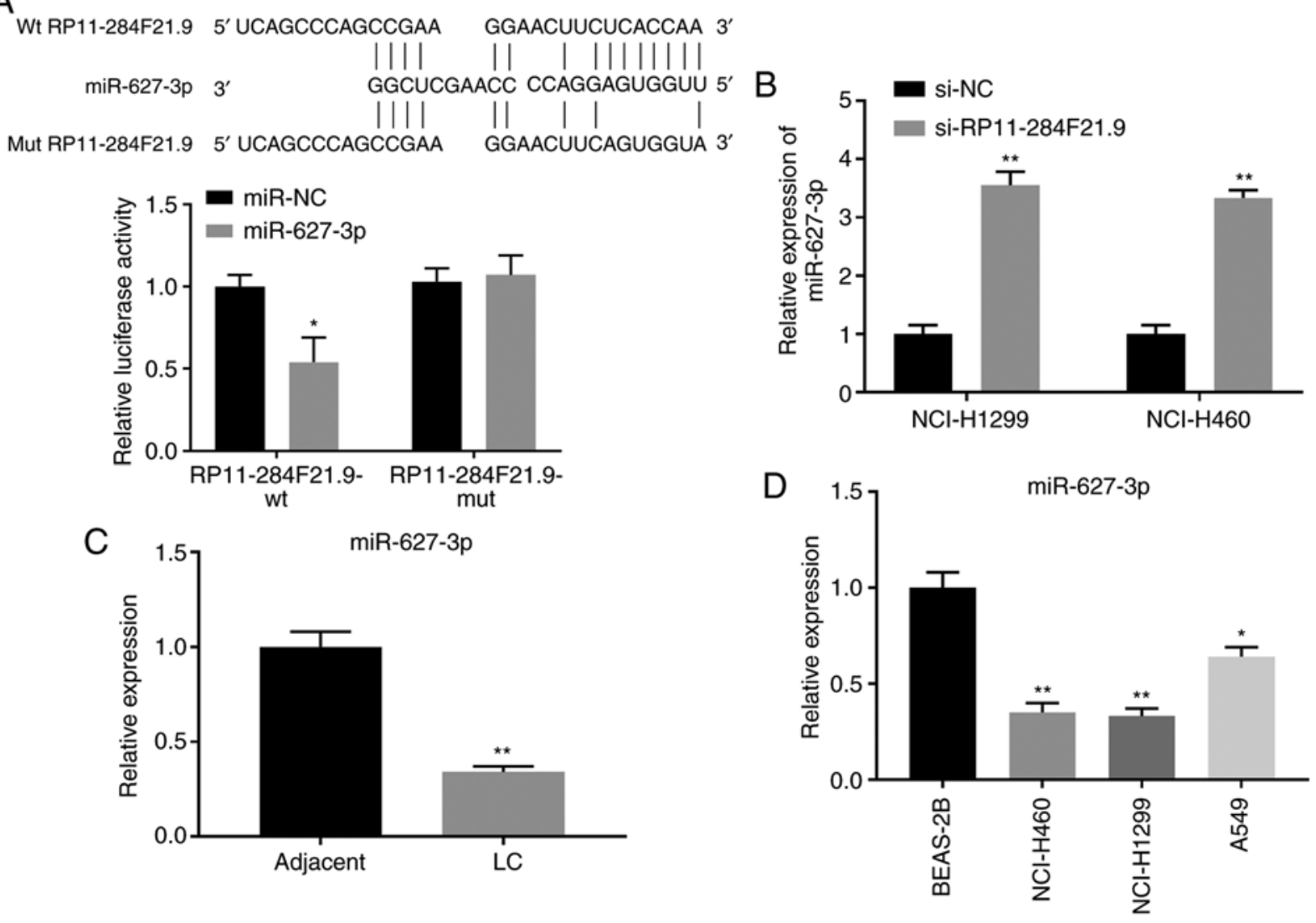

Figure 3. RP11-284F21.9 directly interacts with miR-627-3p. (A) Binding site between RP11-284F21.9 and miR-627-3p that was identified using the DIANA tools, and a luciferase reporter assay was conducted in pmirGLO-RP11-284F21.9-wt or mut treated 293 cells in the presence of miR-627-3p mimics or miR-NC (n=3). ${ }^{*} \mathrm{P}<0.05$ vs. miR-NC. (B) Expression of miR-627-3p in NCI-H1299 and NCI-H460 cells transfected with si-RP11-284F21.9 was analyzed using RT-qPCR. ${ }^{* *} \mathrm{P}<0.01$ vs. si-NC ( $\mathrm{n}=3$ ). miR-627-3p expression in (C) LC tissues and (D) NCI-H460, NCI-H1299 and A549 cells, compared with adjacent healthy tissues and normal lung epithelial cells, was analyzed using RT-qPCR $(n=3) .{ }^{*} \mathrm{P}<0.05,{ }^{* *} \mathrm{P}<0.01$ vs. adjacent tissue or BEAS-2B cells. NC, negative control; siRNA, small interfering RNA; wt, wild-type; mut, mutant; miR, microRNA; LC, lung carcinoma.

miR-627-3p inhibitor restored the reduction in the number of NCI-H1299 and NCI-H460 cells that migrated through the Transwell membrane induced by si-RP11-284F21.9 treatment (Fig. 4F). These data indicated the participation of miR-627-3p in the RP11-284F21.9-mediated invasive effect.

The qPCR assay results identified that both MMP2 and MMP9 expression levels were restored in RP11-284F21.9-downregulated cells when miR-627-3p was inhibited, compared with the miR-NC group (Fig. S3). In addition, transfection with miR-627-3p inhibitor also diminished the pro-apoptosis effect of si-RP11-284F21.9 in both NCI-H1299 and NCI-H460 cells (Fig. 4E). Therefore, it was suggested that RP11-284F21.9 promoted the proliferation and invasion, as well as suppressed the apoptosis of lung carcinoma cells by inhibiting the expression of miR-627-3p.

RP11-284F21.9 regulates CCAR1 via targeting miR-627-3p. To further evaluate how RP11-284F21.9 exerts an oncogenic role via miR-627-3p, the publicly available algorithms of TargetScan (http://www.targetscan.org/) and miRDB were used, which identified CCAR1 as a potential target for miR-627-3p (Fig. 5A). In order to validate this prediction, miR-627-3p mimic was transfected into 293 cells and the transfection efficiency was assessed. The results demonstrated that transfection of miR-627-3p mimic increased the expression of miR-627-3p by $>70$ times compared with cells transfected with miR-NC (Fig. S4).

After validating the upregulation of miR-627-3p mimic, a CCAR1-wt vector was constructed, which contained the wt binding site between miR-627-3p and the CCAR1 3'-UTR, and CCAR1-mut vector containing the mut sequence (Fig. 5A). The results from luciferase reporter assays indicated that, compared with the miR-NC group, the miR-627-3p mimic significantly decreased the luciferase activity of CCAR1-wt treated cells but not the CCAR1-mut treated cells, suggesting a direct binding of miR-627-3p to the 3'-UTR of CCAR1 (Fig. 5B). Increased expression levels of CCAR1 were present in the lung carcinoma tissues compared with the adjacent healthy tissues (Fig. 5C). Moreover, a significant decrease in both mRNA and protein expression levels of CCAR1 was detected upon transfecting NCI-H1299 and NCI-H460 cells with miR-627-3p mimics (Fig. 5D and E). Thus, CCAR1 may be a direct target of miR-627-3p in lung carcinoma cells and tissues.

RP11-284F21.9 knockdown inhibits tumor growth and the expression of CCARI in vivo. In order to investigate the effect of RP11-284F21.9 on in vivo tumorigenicity, NCI-H1299 cells were transfected with si-NC or si-RP11-284F21.9 and injected into the nude mice. After 2 weeks, a significantly 
A

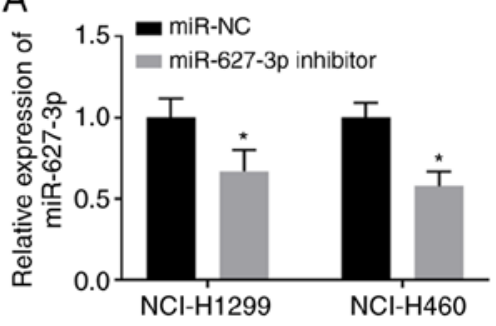

B

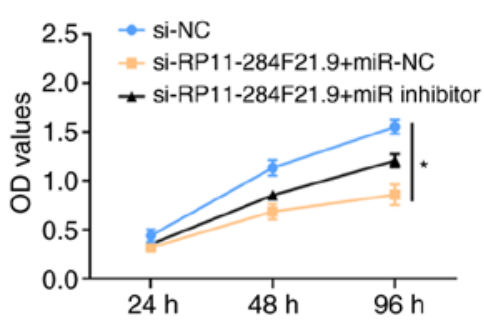

C

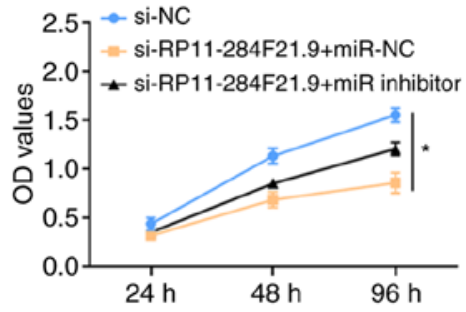

D

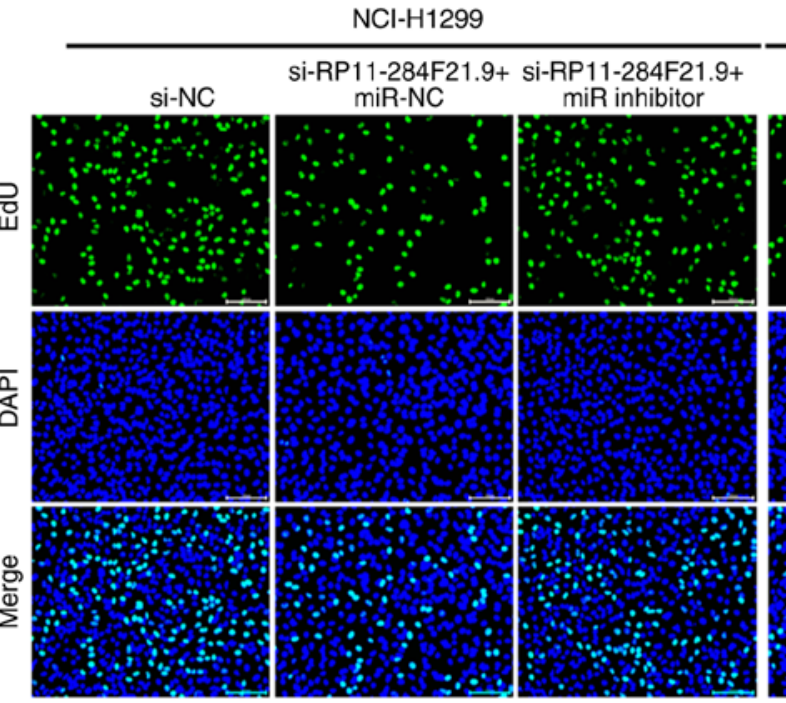

E
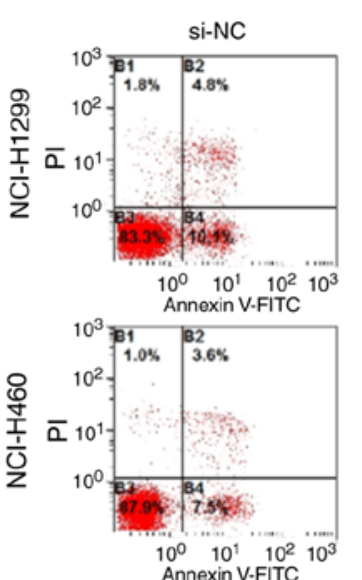
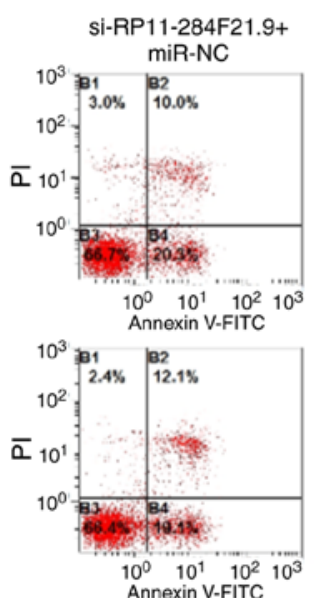

si-NC
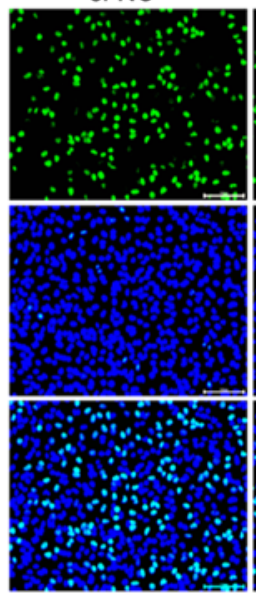

si-RP11-284F21.9+ $\mathrm{miR}$ inhibitor
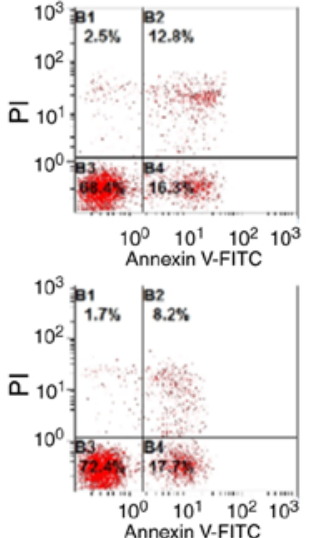

$\mathrm{NCl}-\mathrm{H} 460$

si-RP11-284F21.9+ si-RP11-284F21.9+

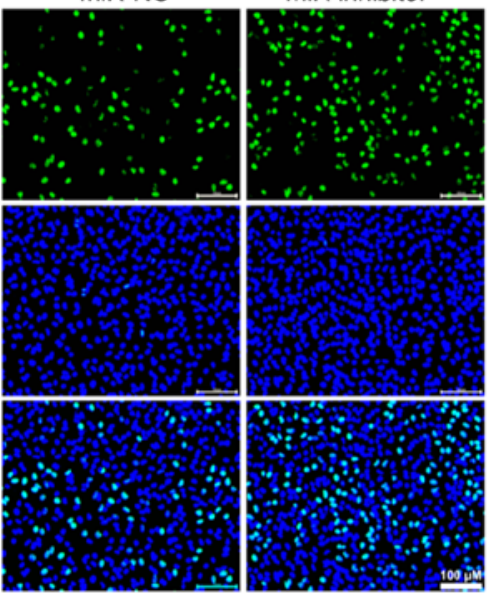

F

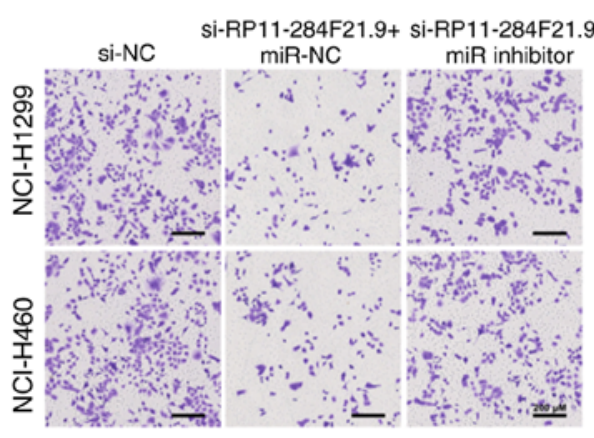

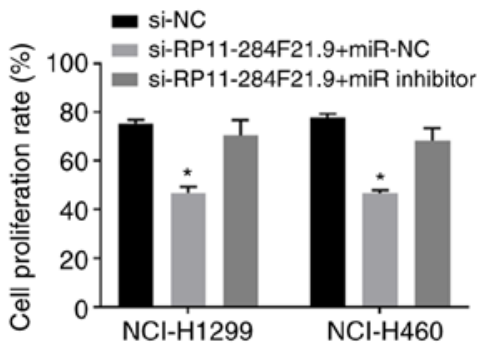
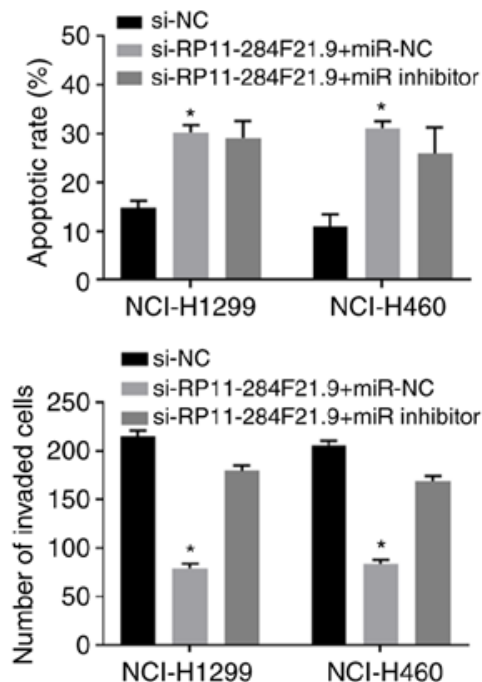

Figure 4. RP11-284F21.9 regulates proliferation and invasiveness in lung carcinoma cells via miR-627-3p. (A) Expression of miR-627-3p in NCI-H1299 and NCI-H460 cells transfected with miR-NC or miR-627-3p inhibitor was detected using RT-qPCR analysis (n=3). *P<0.05 vs. miR-NC. Cell Counting Kit-8 assay was performed in (B) NCI-H1299 and (C) NCI-H460 cells stably transfected with si-RP11-284F21.9 in the presence of miR-NC or miR-627-3p inhibitor $(n=5)$. (D) EdU assay was performed in NCI-H1299 and NCI-H460 cells stably transfected with si-RP11-284F21.9 in the presence of miR-NC or miR-627-3p inhibitor. Magnification, x200. (E) Flow cytometry analysis was performed in NCI-H1299 and NCI-H460 cells stably transfected with si-RP11-284F21.9 in the presence of miR-NC or miR-627-3p inhibitor $(n=3)$. (F) Transwell assay was performed in NCI-H1299 and NCI-H460 cells stably transfected with si-RP11-284F21.9 in the presence of miR-NC or miR-627-3p inhibitor. Magnification, $x 200(n=3)$. * $P<0.05$ vs. si-NC. NC, negative control; siRNA, small interfering RNA; OD, optical density; miR, microRNA. 
A
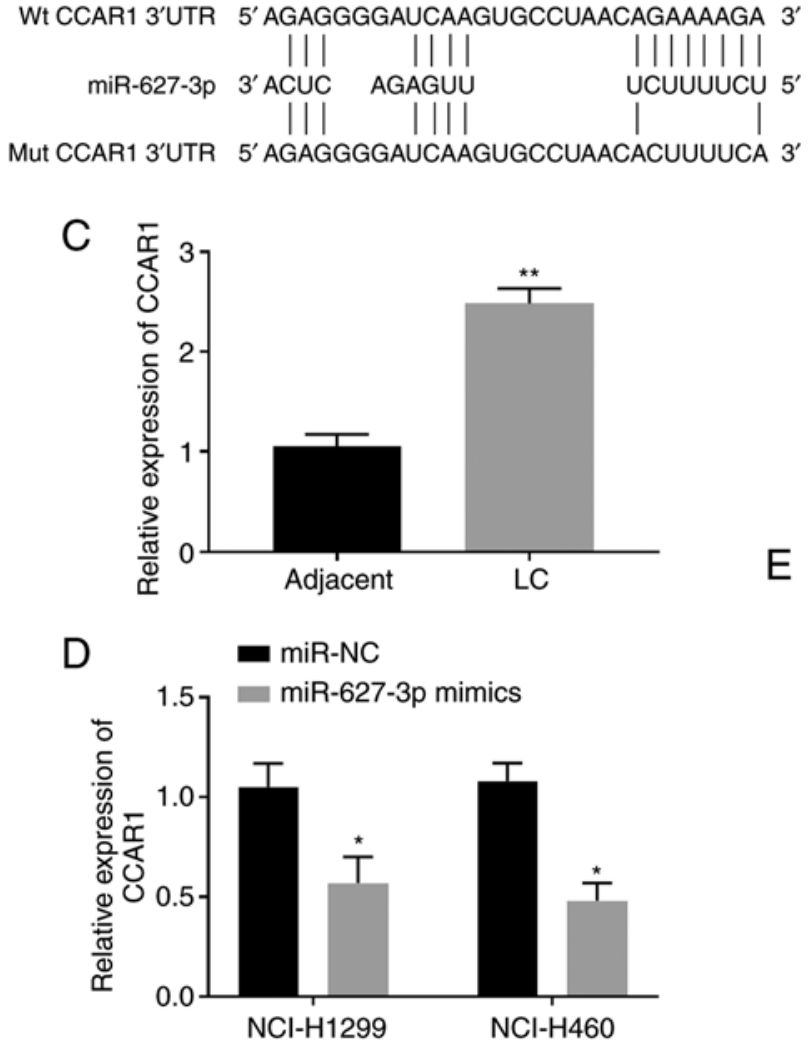

$\mathrm{B}$

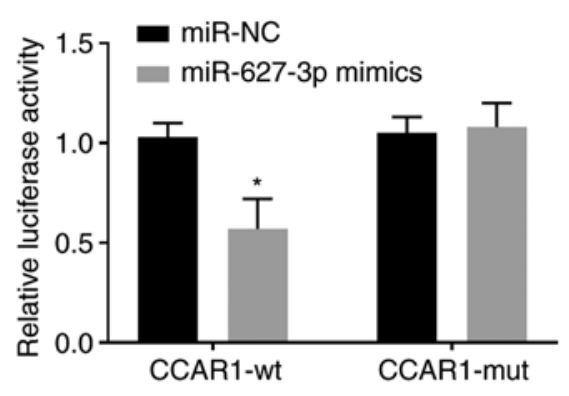

E

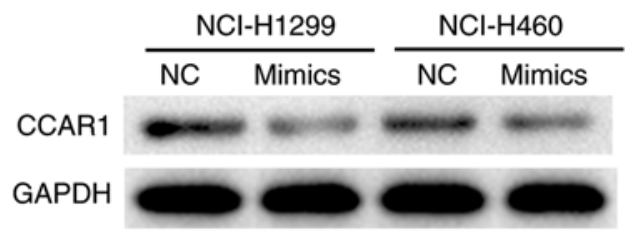

Figure 5. miR-627-3p directly targets CCAR1. (A) Bioinformatic analysis of the predicted binding sites between the CCAR1 3'-untranslated region and miR-627-3p. (B) Luciferase reporter assay in CCAR1-wt or CCAR1-mut treated 293 cells in the presence of miR-NC or miR-627-3p mimic $(\mathrm{n}=3)$. ${ }^{*} \mathrm{P}<0.05$ vs. miR-NC. (C) CCAR1 expression in LC tissues compared with adjacent healthy tissues was analyzed using RT-qPCR ( $\mathrm{n}=13)$. ${ }^{* *} \mathrm{P}<0.01 \mathrm{vs}$. adjacent tissue. Expression of CCAR1 in NCI-H1299 and NCI-H460 cells transfected with miR-NC or miR-627-3p mimics was detected using (D) RT-qPCR and (E) western blotting ( $n=3)$. "P<0.05 vs. miR-NC. miR, microRNA; NC, negative control; wt, wild-type; mut, mutant; RT-qPCR, reverse transcription-quantitative PCR; CCAR1, cell division cycle and apoptosis regulator $1 ; \mathrm{LC}$, lung carcinoma.

slower proliferative rate of the tumors was observed in the si-RP11-284F21.9 group compared with the si-NC group (Fig. 6A and B). Furthermore, the tumor volume and weight were significantly decreased in the si-RP11-284F21.9 group compared with the control group (Fig. 6A and B). RT-qPCR analysis also demonstrated that, compared with the si-NC group, the tumors in the si-RP11-284F21.9 group expressed higher levels of miR-627-3p (Fig. 6C) and lower levels of CCAR1 (Fig. 6D), providing further evidence to the existence of the RP11-284F21.9/miR-627-3p/CCAR1 regulatory axis in lung carcinoma tumor tissues.

\section{Discussion}

The present study investigated the function of RP11-284F21.9 in lung carcinoma. It was initially found that RP11-284F21.9 was significantly upregulated in both lung cancer tissues and cell lines. Following the deduction of a potential oncogenic role of this lncRNA, si-RP11-284F21.9 was transfected into NCI-H460 and NCI-H1299 cells, and it was demonstrated that knockdown of RP11-284F21.9 inhibited the proliferation and invasion, while promoting apoptosis of lung carcinoma cells. In the mechanistic studies, using online prediction tools and in vitro assays, the results indicated that miR-627-3p directly interacts with RP11-284F21.9 by binding to its 3 '-UTR.
The function of miR-627 was initially reported in colorectal cancer (CRC). Padi et al (20) found that when upregulated by calcitriol, miR-627 targets the histone demethylase Jumonji domain containing $1 \mathrm{~A}$ to increase methylation of histone H3K9 and suppresses the proliferative factors of CRC cells, thus inhibiting the proliferation of CRC both in vitro and in vivo. Moreover, in CRC, Sun et al (21) discovered the role of miR-627 in vitamin D-enhanced efficacy of irinotecan via inhibition of the cytochrome P450 enzyme-mediated intratumoral drug metabolism. miR-627 is also reported to be a potential non-invasive diagnostic marker in gastric and breast cancer types $(22,23)$. In pulmonary diseases, miR-627 is downregulated in patients with chronic obstructive pulmonary disease and targets the high-mobility group box protein 1 to inhibit its expression, thus improving transforming growth factor- $\beta 1$-induced pulmonary fibrosis $(24,25)$. The present results demonstrated the inhibitory effect of RP11-284F21.9 on the expression of miR-627-3p. In addition, it was identified that the miR-627-3p inhibitor can neutralize the anti-tumor effects of RP11-284F21.9 knockdown, indicating that RP11-284F21.9 promotes the proliferation and invasiveness of lung carcinoma cells partially by regulating miR-627-3p. This anti-tumor role of miR-627-3p under the regulation of RP11-284F21.9 in lung carcinoma tissues and cells is in accordance with the previous aforementioned findings on human CRC, gastric and breast cancer types. 
A
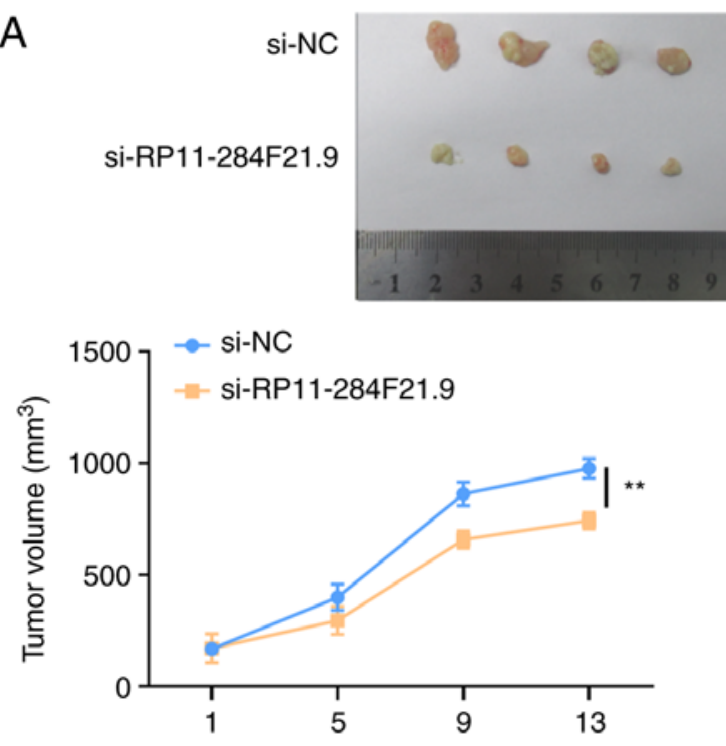

B
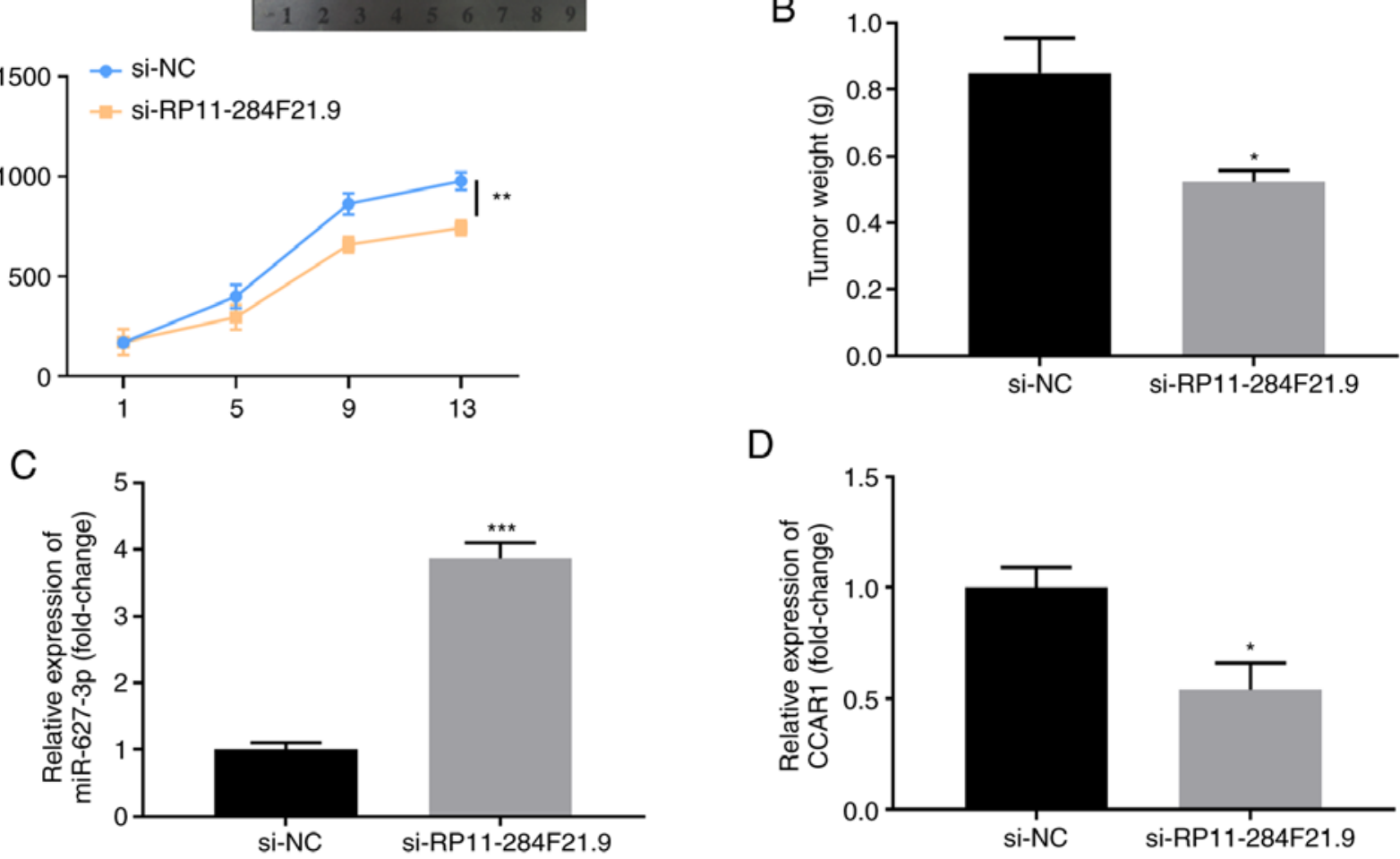

Figure 6. RP11-284F21.9 knockdown inhibits tumor growth in vivo. (A) Macroscopic image of xenografted tumors. (B) Tumor volume in nude mice injected with NCI-H1299 cells transfected with si-NC or si-RP11-284F21.9, measured over 2 weeks $(n=5)$. (C) Weight of tumors in nude mice at 2 weeks after injection of NCI-H1299 cells transfected with si-NC or si-RP11-284F21.9 ( $\mathrm{n}=5)$. Expression levels of (D) miR-627-3p and (E) CCAR1 in the tumor tissues from nude mice injected with NCI-H1299 cells transfected with si-NC or si-RP11-284F21.9 for 2 weeks were detected using reverse transcription-quantitative PCR (n=5). ${ }^{*} \mathrm{P}<0.05,{ }^{* *} \mathrm{P}<0.01,{ }^{* * *} \mathrm{P}<0.001$ vs. si-NC. miR, microRNA; NC, negative control; sh, short hairpin RNA; CCAR1, cell division cycle and apoptosis regulator 1.

Using the publicly available RNA interaction prediction algorithms, the current study identified that CCAR1, which was initially shown as the target gene of miR-627-3p, is also regulated by RP11-284F21.9. Furthermore, the regulatory axis of RP11-284F21.9/miR-627-3p/CCAR1 exists in the lung carcinoma cells both in vitro and in vivo in the tumor growth model. The interaction between RP11-284F21.9 and miR-627-3p, and the interaction between miR-627-3p and CCAR1 were demonstrated by the dual-luciferase assay. Although this method has been used to validate RNA-RNA interactions in previous studies (26-28), other assays, such as RNA pull-down and RNA binding protein immunoprecipitation that would provide more direct evidence for the RNA-RNA and RNA-protein interactions, should be performed.

CCAR1 was initially reported as a protein essential for cancer cell apoptosis induced by retinoids or chemotherapeutics, such as Adriamycin and etoposide (29). Subsequently, Kim et al (30) revealed that this protein functions as a transcriptional co-activator of nuclear receptors. In human breast cancer cells, as CCAR1 interacts and cooperates with the co-activators of estrogen receptor signaling, it promotes the estrogen-dependent proliferation of cancer cells. In CRC cells, Ou et al (31) reported that CCAR1 can be recruited by $\beta$-catenin to act as a co-activator for the transcriptional activation of lymphoid enhancer binding factor 1.CCAR1 is essential for the expression of Wnt target genes, as well as the neoplastic transformation of CRC cells $(31,32)$. In gastric cancer cells, researchers have revealed the cooperation between CCAR1 and $\beta$-catenin, which leads to the promotion of the proliferation and migration of cancer cells (33). In lung cancer, CCAR1 was reported to be an effector of Doxorubicin-induced apoptosis (34). Moreover, Muthu et al (35) demonstrated that certain chemical compounds that bind with CCAR1 can increase the expression of CCAR1 and induce apoptosis. However, a contradictory conclusion was reported in a recent study, which observed that CCAR1 was promoted by serine and arginine rich splicing factor 5 , which is activated by glucose intake, and further enhanced tumorigenesis by increasing the glucose consumption rate (36). Corroborating this finding, in the current study, via the targeting of miR-627-3p, the expression of CCAR1 was positively associated with that of RP11-284F21.9, suggesting a carcinogenic role in lung carcinoma tissues and cells. However, a limitation and future direction of the present study is to investigate the function of CCAR1 in lung cancer, including the identification of its interactome and the potential pathways that trigger the tumorigenesis of lung cancer. 
In conclusion, the present results demonstrated the promoting effect of RP11-284F21.9 on the proliferation and invasion of lung carcinoma cells. It was found that the oncogenic function of RP11-284F21.9 was partially mediated via the RP11-284F21.9/miR-627-3p/CCAR1 axis in both lung cancer cells and tissues. By investigating the role and mechanism of a newly identified lncRNA, the current study revealed a novel treatment target and a potential therapeutic strategy for patients with lung carcinoma.

\section{Acknowledgements}

Not applicable.

\section{Funding}

This work was supported by the Natural Science Foundation of Shaanxi Province (grant no. 2018JM7026), Xi'an Science and Technology Project [grant no. 201805102YX10SF36(3)] and the Fundamental Research Funds for the Central Universities in Xi'an Jiaotong University (grant no. xjj2018272).

\section{Availability of data and materials}

The datasets used and/or analyzed during the current study are available from the corresponding author on reasonable request.

\section{Authors' contributions}

DL and YW conceived and designed the experiments. DL, LW and JF performed the experiments. DL, LL and YS analyzed and interpreted the data. DL wrote the manuscript. LL and YW revised the manuscript. All authors read and approved the final manuscript.

\section{Ethics approval and consent to participate}

All the tissue samples were obtained with written informed consent from the patients. The protocol was approved by The First Affiliated Hospital of Xi'an Jiaotong University (approval no. 201810053). Animal care and study were approved by the Institutional Animal Care and Use Committee of The First Affiliated Hospital of Xi'an Jiaotong University (approval no. 201902013).

\section{Patient consent for publication}

Not applicable.

\section{Competing interests}

The authors declare that they have no competing interests.

\section{References}

1. Siegel RL, Miller KD and Jemal A: Cancer statistics, 2019. CA Cancer J Clin 69: 7-34, 2019.

2. Chen W, Zheng R, Baade PD, Zhang S, Zeng H, Bray F, Jemal A, $\mathrm{Yu}$ XQ and He J: Cancer statistics in China, 2015. CA Cancer J Clin 66: 115-132, 2016.

3. Chheang $\mathrm{S}$ and Brown K: Lung cancer staging: Clinical and radiologic perspectives. Semin Intervent Radiol 30: 99-113, 2013.
4. Pao W and Girard N: New driver mutations in non-small-cell lung cancer. Lancet Oncol 12: 175-180, 2011.

5. Iyer MK, Niknafs YS, Malik R, Singhal U, Sahu A, Hosono Y, Barrette TR, Prensner JR, Evans JR, Zhao S, et al: The landscape of long noncoding RNAs in the human transcriptome. Nat Genet 47: 199-208, 2015.

6. Alizadeh A, Moztarzadeh F, Ostad SN, Azami M, Geramizadeh B, Hatam G, Bizari D, Tavangar SM, Vasei M and Ai J: Synthesis of calcium phosphate-zirconia scaffold and human endometrial adult stem cells for bone tissue engineering. Artif Cells Nanomed Biotechnol 44: 66-73, 2016.

7. Peng W, Wang J, Shan B, Peng Z, Dong Y, Shi W, He D, Cheng Y, Zhao W, Zhang C, et al: Diagnostic and prognostic potential of circulating long non-coding RNAs in non small cell lung cancer. Cell Physiol Biochem 49: 816-827, 2018.

8. Du Z, Fei T, Verhaak RG, Su Z, Zhang Y, Brown M, Chen Y and Liu XS: Integrative genomic analyses reveal clinically relevant long noncoding RNAs in human cancer. Nat Struct Mol Biol 20: 908-913, 2013.

9. Huarte M: The emerging role of lncRNAs in cancer. Nat Med 21: 1253-1261, 2015.

10. Tian X and Xu G: Clinical value of lncRNA MALAT1 as a prognostic marker in human cancer: Systematic review and meta-analysis. BMJ Open 5: e008653, 2015.

11. Wang JZ, Xiang JJ, Wu LG, Bai YS, Chen ZW, Yin XQ, Wang Q, Guo WH, Peng Y, Guo H and Xu P: A genetic variant in long non-coding RNA MALAT1 associated with survival outcome among patients with advanced lung adenocarcinoma: A survival cohort analysis. BMC Cancer 17: 167, 2017.

12. Loewen G, Jayawickramarajah J, Zhuo Y and Shan B: Functions of lncRNA HOTAIR in lung cancer. J Hematol Oncol 7: 90, 2014.

13. Liu XH, Liu ZL, Sun M, Liu J, Wang ZX and De W: The long non-coding RNA HOTAIR indicates a poor prognosis and promotes metastasis in non-small cell lung cancer. BMC Cancer 13: 464, 2013.

14. Nakagawa T, Endo H, Yokoyama M, Abe J, Tamai K, Tanaka N, Sato I, Takahashi S, Kondo T and Satoh K: Large noncoding RNA HOTAIR enhances aggressive biological behavior and is associated with short disease-free survival in human non-small cell lung cancer. Biochem Biophys Res Commun 436: 319-324, 2013.

15. Nie W, Ge HJ, Yang XQ, Sun X, Huang H, Tao X, Chen WS and Li B: LncRNA-UCA1 exerts oncogenic functions in non-small cell lung cancer by targeting miR-193a-3p. Cancer Lett 371: 99-106, 2016.

16. Cheng N, Cai W, Ren S, Li X, Wang Q, Pan H, Zhao M, Li J, Zhang Y, Zhao C, et al: Long non-coding RNA UCA1 induces non-T790M acquired resistance to EGFR-TKIs by activating the AKT/mTOR pathway in EGFR-mutant non-small cell lung cancer. Oncotarget 6: 23582-23593, 2015.

17. Ashouri A, Sayin VI, Van den Eynden J, Singh SX, Papagiannakopoulos T and Larsson E: Pan-cancer transcriptomic analysis associates long non-coding RNAs with key mutational driver events. Nat Commun 7: 13197, 2016.

18. Dwyer CA, Bi WL, Viapiano MS and Matthews RT: Brevican knockdown reduces late-stage glioma tumor aggressiveness. J Neurooncol 120: 63-72, 2014.

19. Livak KJ and Schmittgen TD: Analysis of relative gene expression data using real-time quantitative PCR and the 2(-Delta Delta C(T)) method. Methods 25: 402-408, 2001.

20. Padi SK, Zhang Q, Rustum YM, Morrison C and Guo B: MicroRNA-627 mediates the epigenetic mechanisms of vitamin D to suppress proliferation of human colorectal cancer cells and growth of xenograft tumors in mice. Gastroenterology 145: 437-446, 2013.

21. Sun M, Zhang Q, Yang X, Qian SY and Guo B: Vitamin D enhances the efficacy of irinotecan through miR-627-mediated inhibition of intratumoral drug metabolism. Mol Cancer Ther 15: 2086-2095, 2016.

22. Shin VY, Ng EK, Chan VW, Kwong A and Chu KM: A three-miRNA signature as promising non-invasive diagnostic marker for gastric cancer. Mol Cancer 14: 202, 2015.

23. Cao J, Luo C, Yan R, Peng R, Wang K, Wang P, Ye H and Song C: rs15869 at miRNA binding site in BRCA2 is associated with breast cancer susceptibility. Med Oncol 33: 135, 2016.

24. Li J, Kong X, Jiang S, Liao W, Zhang Z, Song J, Liang Y and Zhang W: miR-627/HMGB1/NF- $\kappa \mathrm{B}$ regulatory loop modulates TGF- $\beta 1$-induced pulmonary fibrosis. J Cell Biochem 120: 2983-2993, 2019. 
25. Musri MM, Coll-Bonfill N, Maron BA, Peinado VI, Wang RS, Altirriba J, Blanco I, Oldham WM, Tura-Ceide O, García-Lucio J, et al: MicroRNA dysregulation in pulmonary arteries from chronic obstructive pulmonary disease. relationships with vascular remodeling. Am J Respir Cell Mol Biol 59: 490-499, 2018

26. Lu Z, Yu Y, Ding X, Jin D, Wang G, Zhou Y, Zhu Y, Na L, He Y and Wang Q: LncRNA FLJ33360 accelerates the metastasis in hepatocellular carcinoma by targeting miRNA-140/MMP9 axis. Am J Transl Res 12: 583-591, 2020.

27. Huang W, Huang F, Lei Z and Luo H: LncRNA SNHG11 promotes proliferation, migration, apoptosis, and autophagy by regulating hsa-miR-184/AGO2 in HCC. Onco Targets Ther 13: 413-421, 2020

28. Sui G, Zhang B, Fei D, Wang H, Guo F and Luo Q: The lncRNA SNHG3 accelerates papillary thyroid carcinoma progression via the miR-214-3p/PSMD10 axis. J Cell Physiol: Feb 11, 2020 (Epub ahead of print).

29. Rishi AK, Zhang L, Boyanapalli M, Wali A, Mohammad RM Yu Y, Fontana JA, Hatfield JS, Dawson MI, Majumdar AP and Reichert U: Identification and characterization of a cell cycle and apoptosis regulatory protein-1 as a novel mediator of apoptosis signaling by retinoid CD437. J Biol Chem 278: 33422-33435, 2003.

30. Kim JH, Yang CK, Heo K, Roeder RG, An W and Stallcup MR: CCAR1, a key regulator of mediator complex recruitment to nuclear receptor transcription complexes. Mol Cell 31: 510-519, 2008.

31. Ou CY, Kim JH, Yang CK and Stallcup MR: Requirement of cell cycle and apoptosis regulator 1 for target gene activation by Wnt and beta-catenin and for anchorage-independent growth of human colon carcinoma cells. J Biol Chem 284: 20629-20637, 2009.
32. Yan L, You WQ, Sheng NQ, Gong JF, Hu LD, Tan GW, Chen HQ and Wang ZG: A CREB1/miR-433 reciprocal feedback loop modulates proliferation and metastasis in colorectal cancer. Aging (Albany NY) 10: 3774-3793, 2018.

33. Chang TS, Wei KL, Lu CK, Chen YH, Cheng YT, Tung SY, Wu CS and Chiang MK: Inhibition of CCAR1, a coactivator of $\beta$-catenin, suppresses the proliferation and migration of gastric cancer cells. Int J Mol Sci 18: 460, 2017.

34. Cheriyan VT, Alsaab H, Sekhar S, Venkatesh J, Mondal A, Vhora I, Sau S, Muthu M, Polin LA, Levi E, et al: A CARP-1 functional mimetic compound is synergistic with BRAF-targeting in non-small cell lung cancers. Oncotarget 9: 29680-29697, 2018.

35. Muthu M, Somagoni J, Cheriyan VT, Munie S, Levi E, Ashour AE, Yassin AE, Alafeefy AM, Sochacki P, Polin LA, et al: Identification and testing of novel CARP-1 functional mimetic compounds as inhibitors of non-small cell lung and triple negative breast cancers. J Biomed Nanotechnol 11: 1608-1627, 2015

36. Chen Y, Huang Q, Liu W, Zhu Q, Cui CP, Xu L, Guo X, Wang P, Liu J, Dong G, et al: Mutually exclusive acetylation and ubiquitylation of the splicing factor SRSF5 control tumor growth. Nat Commun 9: 2464, 2018.

This work is licensed under a Creative Commons Attribution-NonCommercial-NoDerivatives 4.0 International (CC BY-NC-ND 4.0) License. 